\title{
Cartilage Shield Tympanoplasty: A Retrospective Chart Review of 69 Cases
}

\author{
${ }^{1}$ Simple Patadia, ${ }^{2}$ Amitkumar Keshri, ${ }^{3}$ Saurin Shah
}

\begin{abstract}
Objective: Cartilage shield tympanoplasty (CST) is an acknowledged procedure to repair total tympanic membrane perforations. The main objective of this study was to share our experience of CST, in form of its technique, graft uptake and hearing outcomes.
\end{abstract}

Study design: Retrospective chart review.

Setting: Tertiary care hospital, Sanjay Gandhi Postgraduate Institute of Medical Sciences, Lucknow, Uttar Pradesh, India.

Patients: A total of 69 cases of type 1 CST, from January 2013 to March 2014. We followed all patients for a minimum period of 6 months.

\section{Intervention: Therapeutic.}

Main outcome measures: Graft uptake rate, along with preand postoperative pure tone audiogram air bone gap (ABG) and postoperative complications, was evaluated. We compared ABG using Student's t-test.

Results: Graft uptake was seen in 68 cases (98.5\%). The mean pre- and postoperative pure tone audiometry (PTA)-ABG was $37.58 \pm 6.43 \mathrm{~dB}$ and $20.19 \pm 8.14 \mathrm{~dB}$, respectively. Hearing improvement was maximum at $2 \mathrm{kHz}$ with mean postoperative value of $17.73 \mathrm{~dB}$, and the least improvement was seen at $8 \mathrm{kHz}$ with value of $30 \mathrm{~dB}$ in postoperative period.

Conclusion: The graft uptake rate was excellent, and hearing results were satisfactory. Cartilage shield tympanoplasty should be a recommended procedure for total perforation, subtotal perforation and revision cases. However, long-term results are still awaited.

Keywords: Air-bone gap, Cartilage shield tympanoplasty, Graft uptake.

How to cite this article: Patadia S, Keshri A, Shah S. Cartilage Shield Tympanoplasty: A Retrospective Chart Review of 69 Cases. Int J Otorhinolaryngol Clin 2015;7(3):105-108.

\section{Source of support: Nil}

Conflict of interest: None

\section{INTRODUCTION}

The main aim of tympanoplasty is to eradicate middle ear disease, restore middle ear aeration and to maintain

\footnotetext{
1,3 Senior Resident, ${ }^{2}$ Assistant Professor

${ }^{1-3}$ Department of Neurosurgery, Sanjay Gandhi Postgraduate Institute of Medical Sciences, Lucknow, Uttar Pradesh, India
}

Corresponding Author: Simple Patadia, Senior Resident Department of Neurosurgery, Sanjay Gandhi Postgraduate Institute of Medical Sciences, Lucknow, Uttar Pradesh, India Phone: 8004904440, e-mail: simplepatadia@gmail.com the hearing mechanism. Zöllner and Wullstein, from Germany, first introduced tympanoplasty in early fifties. ${ }^{1}$

The various graft materials used to repair tympanic membrane are skin, temporalis fascia, fascia lata, perichondrium, cartilage, vein and dura mater. ${ }^{2}$ The most commonly employed material till date is temporalis fascia with a successful closure rate of approximately $90 \%$ of primary tympanoplasty. ${ }^{3}$

The use of cartilage in middle ear surgery dates back to 1959 , when it was used in management of retraction pockets. ${ }^{4,5}$ Cartilage is the material of choice with chronic Eustachian tube dysfunction due to its increased stability. ${ }^{6}$

Heermann was the first to introduce cartilage palisade technique in $1962 .{ }^{7}$ Cartilage shield tympanoplasty (CST) was first reported in literature by Duckert et al in $1995 .{ }^{6}$ Recently, the use of cartilage as a shield tympanoplasty is popularized by Cavaliere and Aidonis., ${ }^{2,8}$ Cartilage grafts are the treatment of choice in posterior and attic retraction pockets. ${ }^{9}$

However, the use of cartilage has also been criticized due to concerns of decreased middle ear space and postoperative surveillance in cholesteatoma cases. ${ }^{10}$ The various other techniques used are palisade, cartilage island, and CST. ${ }^{9}$ The use of cartilage, both tragal and conchal as a shield, at the level of handle of malleus is accounted in this study. The purpose of this study is to share our experience of CST, in cases of subtotal and total perforation, tympanosclerosis and revision cases.

\section{MATERIALS AND METHODS}

A retrospective analysis of 69 patients who underwent CST from January to March 2013 was done. Both primary and revision cases were included in the study. Only type 1 tympanoplasty, in which graft was directly placed on handle of malleus was taken into study group. Both tragal and conchal cartilage were used in reconstruction. Antrum was not opened in any case.

\section{Surgical Technique}

All patients underwent procedure under general anesthesia. A postauricular approach with Wilde's incision was used. Local infiltration was done with 1: $200.0002 \%$ xylocaine plus adrenaline prepared solution in postauricular region and in external auditory canal. 
After incising the skin, subcutaneous tissue and periosteum, posterior canal wall was incised. Margins of the perforation were freshened. The vascular strip incision was given and tympanomeatal flap was elevated exposing the annulus completely. In case of any canal wall bulge, canaloplasty was performed for adequate exposure. Ossicular chain was properly assessed and round window reflex was checked. If handle of malleus was retracted to promontory, it was nibbled with a malleus nipper. Middle ear and Eustachian tube was filled with antibiotic and steroid impregnated gelfoam.

A $1.5 \mathrm{~cm}$ incision was kept on tragus to harvest tragal cartilage, leaving $2 \mathrm{~mm}$ of cartilage in the dome for cosmesis. For conchal cartilage, a circular piece of cartilage was harvested from the posterior aspect of concha. Perichondrial layer was stripped from both sides. The harvested cartilage was approximately $1.5 \times$ $1 \mathrm{~cm}$. Tragal cartilage was thinned out with the help of cartilage slicer to size of $0.7 \mathrm{~mm}$ thickness. A ' $\mathrm{V}$ ' shaped notch was removed from the cartilage to accommodate the handle of malleus. Cartilage was kept as a shield at the level handle of malleus, under the level of annulus. Deep layer of the temporalis fascia was harvested, spread and kept over the cartilage shield under the level of annulus.

After repositing the tympanomeatal flap, graft was stabilized with gelfoam and antibiotic impregnated wick was kept in external auditory canal. The postauricular incision was closed in two layers and a mastoid dressing was given.

Patients were reviewed in terms of graft uptake, change in preoperative and postoperative mean pure tone audiometry (PTA)-air bone gap (ABG), and postoperative complications. Pure tone audiometry-air bone gap was evaluated for 500, 1000, 2000 and $4000 \mathrm{~Hz}$. Successful graft uptake was defined having no perforation, retraction, or lateralization in postoperative period. Postoperative complications we considered were graft failure, retraction pocket, reperforation, hearing loss, facial nerve injury, cholesteatoma and wound infection.

Statistical analysis of the data was performed using $R$ software and Student's $t$ test was used to compare the differences between pre- and postoperative PTA-ABG.

\section{RESULTS}

There were 42 males and 27 females patients out of 69 cases considered for the study. Mean age of the patients was 26.3 years (12-60 years). Out of 69 cases, primary procedures were $55(79.7 \%)$ and $14(20.3 \%)$ were revision cases.

Sixty patients had dry ear with no active discharge and nine patients had active discharge, at the time of surgery. Cases with total perforation, subtotal perforation, and perforation with tympanosclerotic patch were 8,32 , and 15 , respectively. Out of 14 revision cases, seven cases had moderate to large perforation and the rest seven had subtotal perforation. All patients underwent type 1 CST with the above mentioned technique. Tragal and conchal cartilages were used in 31 and 38 patients respectively for reconstruction.

There were no immediate postoperative complications, such as wound infection, hematoma, facial weakness, and sudden sensorineural hearing loss.

Patients had a minimum follow-up of 6 months (6-19 months). Graft uptake was seen in $98.5 \%$ (68 cases). Failure was observed in one case in which a marginal perforation was seen in anteroinferior quadrant. All patients had improvement in hearing. On follow-up, there was no blunting of anterior sulcus, laterization of graft, retraction pockets, atelectasis or cholesteatoma pearl in any patient.

The mean pre- and postoperative PTA-ABG was $37.58 \pm 6.43 \mathrm{~dB}$ and $20.19 \pm 8.14 \mathrm{~dB}$, respectively (Graph 1). Data analysis of pre- and postoperative

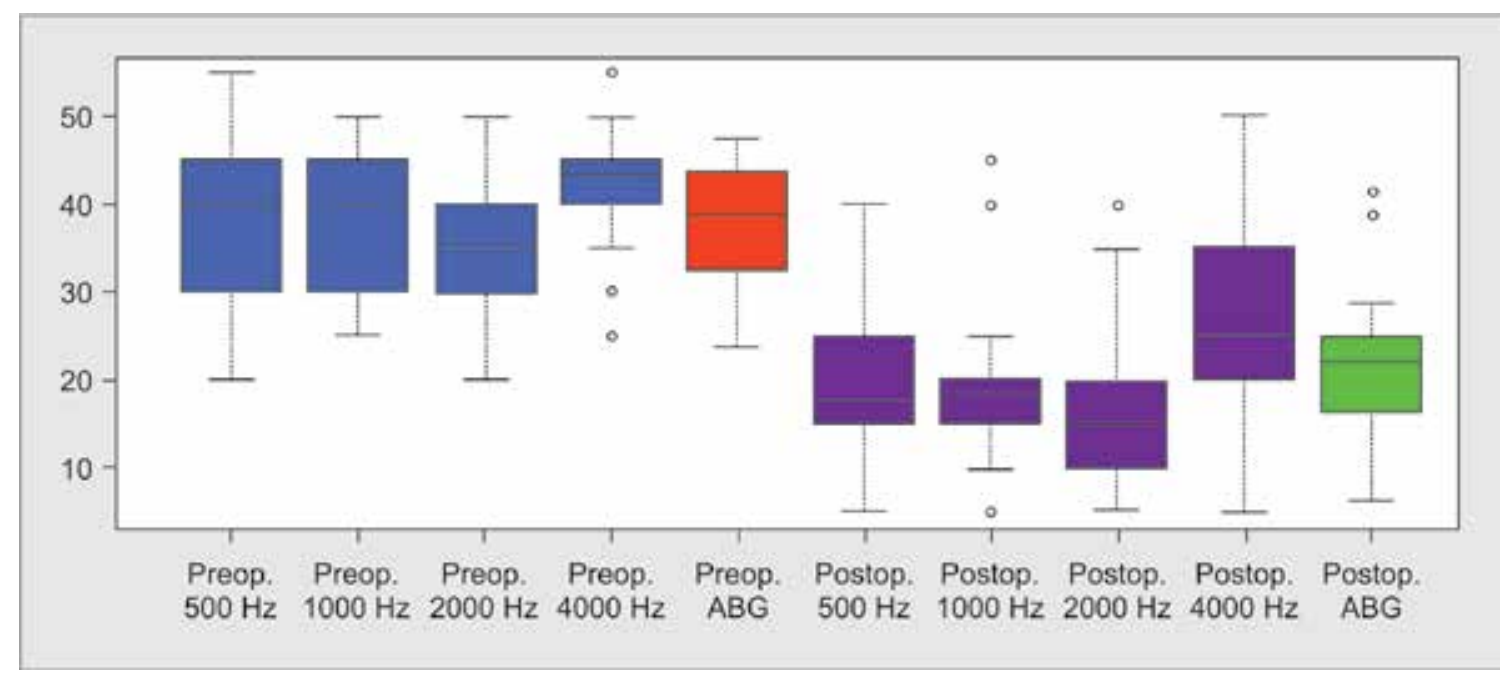

Graph 1: Box plot showing the frequency distribution of hearing loss in preoperative and postoperative period 
ABG in individual frequency is shown in Table 1. Pure tone audiometry-air bone gap was compared using Student's $t$ test $(t=7.33)$. The results showed that the difference between pre- and postoperative PTA-ABG was statistically significant ( $p<0.0001)$. The maximum postoperative PTA-ABG closure was seen at $2 \mathrm{kHz}$ with mean postoperative value of $17.73 \mathrm{~dB}$, and the least improvement was seen at 8 $\mathrm{kHz}$ with value of $30 \mathrm{~dB}$ in postoperative period (Graph 2). Tragal and conchal cartilage both gave a significant improvement in postoperative PTA-ABG of $20.21 \pm 9.61$ and $22.19 \pm 7.98$ respectively.

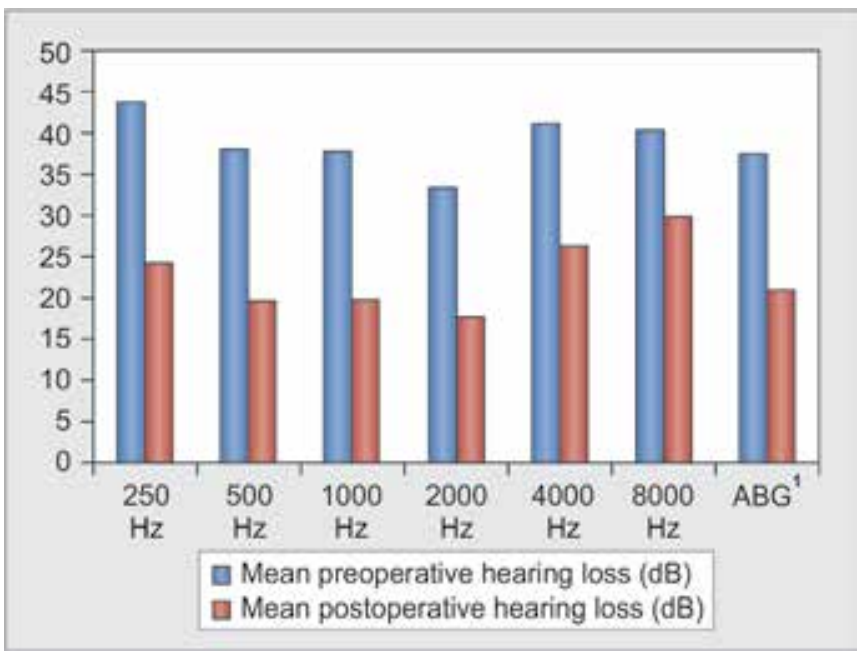

Graph 2: Hearing improvement in individual frequency

\section{DISCUSSION}

As per our study, patients with total perforation, subtotal perforation, perforation with tympanosclerosis and revision cases should be considered for CST. Cartilage grafts are highly resistant to resorption, retraction and are nourished by diffusion. It resists changes in middle ear pressure and prevents lateralization of graft.

In our institute, all patients with discharging ear and revision cases underwent tympanoplasty without mastoidectomy. Literature review also suggests that mastoidectomy may not be necessary in revision tympanoplasty in the absence of cholesteatoma with the use of cartilage. ${ }^{11}$

The graft uptake rate in our study is $98.5 \%$ which is comparable to the results of others as shown in Table 2. Out of 69 cases, one failure was noted in a primary inactive disease, in which the cartilage was displaced and a small anteroinferior perforation was seen in the postoperative follow-up visit. However, patient had significant improvement in hearing. The main reason of failure of graft materials in literature are displacement of graft-medially or laterally, shrinkage of graft material and infection, ${ }^{12}$ however, cartilage resists the above shortcomings.

Iacovou et $\mathrm{al}^{1}$ studied 101 cases of type 1 tympanoplasty with a mean follow-up of 23 months and concluded that the graft uptake rate was as high as $97.2 \%$ and the mean pre- and postoperative PTA-ABG was $31.26 \pm 9.81$

Table 1: Data analysis of preoperative and postoperative ABG for individual frequency

\begin{tabular}{|c|c|c|c|c|c|c|}
\hline Frequency & Mean & Median & 25th percentile & 75th percentile & $\begin{array}{l}\text { Standard } \\
\text { deviation }\end{array}$ & Missing values \\
\hline \multicolumn{7}{|c|}{ Preoperative } \\
\hline $250 \mathrm{~Hz}$ & 43.83 & 45 & 40 & 50 & 9.973 & 3 \\
\hline $500 \mathrm{~Hz}$ & 38.17 & 40 & 30 & 45 & 9.142 & 3 \\
\hline $1000 \mathrm{~Hz}$ & 37.83 & 40 & 31.25 & 45 & 7.507 & 3 \\
\hline $2000 \mathrm{~Hz}$ & 33.17 & 35 & 30 & 38.75 & 7.598 & 3 \\
\hline $3000 \mathrm{~Hz}$ & 39.5 & 40 & 35 & 45 & 7.114 & 3 \\
\hline $4000 \mathrm{~Hz}$ & 41.17 & 40 & 40 & 45 & 7.391 & 3 \\
\hline $8000 \mathrm{~Hz}$ & 40.5 & 40 & 35 & 45 & 11.398 & 3 \\
\hline $\mathrm{ABG}^{1}$ & 37.58 & 38.75 & 32.81 & 43.44 & 6.432 & 3 \\
\hline \multicolumn{7}{|c|}{ Postoperative } \\
\hline $250 \mathrm{~Hz}$ & 24.32 & 25 & 20 & 25 & 10.153 & 11 \\
\hline $500 \mathrm{~Hz}$ & 19.77 & 17.50 & 15 & 23.75 & 8.234 & 11 \\
\hline $1000 \mathrm{~Hz}$ & 19.77 & 20 & 15 & 20 & 8.794 & 11 \\
\hline $2000 \mathrm{~Hz}$ & 17.73 & 15 & 10 & 20 & 8.553 & 11 \\
\hline $4000 \mathrm{~Hz}$ & 26.36 & 25 & 20 & 35 & 12.458 & 11 \\
\hline $8000 \mathrm{~Hz}$ & 30 & 25 & 20 & 36.25 & 10.761 & 11 \\
\hline$A B G^{2}$ & 20.91 & 20.62 & 16.25 & 24.69 & 8.480 & 11 \\
\hline
\end{tabular}

${ }^{1}$ Preoperative $A B G=(500 \mathrm{~Hz}+1000 \mathrm{~Hz}+2000 \mathrm{~Hz}+4000 \mathrm{~Hz}) / 4$

${ }^{2}$ Postoperative $A B G=(500 \mathrm{~Hz}+1000 \mathrm{~Hz}+2000 \mathrm{~Hz}+4000 \mathrm{~Hz}) / 4$ 
Table 2: Review of literature on cartilage shield tympanoplasty ${ }^{16}$

\begin{tabular}{|c|c|c|c|c|c|c|c|}
\hline Study & $\begin{array}{l}\text { Number of } \\
\text { cases (type 1) }\end{array}$ & Graft type & $\begin{array}{l}\text { Mean } \\
\text { follow-up }\end{array}$ & $\begin{array}{l}\text { Graft uptake } \\
\text { rate (\%) }\end{array}$ & $\begin{array}{l}\text { Preoperative } \\
A B G(d B)\end{array}$ & $\begin{array}{l}\text { Postoperative } \\
A B G(d B)\end{array}$ & $p$-value \\
\hline lacovou et al ${ }^{1}$ & 101 & Conchal & 23 months & 97.2 & $31.26 \pm 9.81$ & $16.68 \pm 9.86$ & $<0.0001$ \\
\hline Duckert et $\mathrm{al}^{6}$ & 71 & Conchal & $\begin{array}{l}\text { Minimum } \\
6 \text { months }\end{array}$ & 97 & - & $\begin{array}{l}<10 \mathrm{~dB} \text { in } 82 \% \\
\text { cases }\end{array}$ & - \\
\hline Cavaliere et $\mathrm{al}^{2}$ & 100 & Tragal & 37 months & 99.35 & $36.80 \pm 1.94$ & $6.40 \pm 2.20$ & $<0.0001$ \\
\hline Aidonis et $\mathrm{al}^{8}$ & 62 & Conchal & - & 98.4 & $32.4 \pm 14.1$ & $24 \pm 13.7$ & $<0.005$ \\
\hline Kyrodimos et al ${ }^{16}$ & 52 & Conchal & 12 & 100 & $52.2 \pm 17.7$ & $35.4 \pm 17.9$ & $<0.001$ \\
\hline
\end{tabular}

and $16.68 \pm 9.86$, respectively. Cavaliere et $\mathrm{al}^{2}$ reported 100 cases of type 1 CST with tragal cartilage and the postoperative PTA-ABG was $6.40 \pm 2.20 \mathrm{~dB}$ (Table 2).

The main limitation of this technique is difficulty in postoperative surveillance due to graft opacity, risk of middle ear effusion and residual cholesteatoma. Cartilage being a rigid material is thought to give significant conductive hearing loss, although its hearing results are comparable to other graft material. ${ }^{13,14}$ However, the routine use of CST in all cases is still controversial. In a study by Kulkarni et al, ${ }^{15}$ all patients who underwent type 1 tympanoplasty, had an additional support of cartilage anteriorly, medial to annulus.

The limitation in the study was that mean follow-up in our patient group is 9 months. Long-term results are still awaited. However, there are evidences that postoperative hearing actually improves with time in case of cartilage tympanoplasty. ${ }^{4}$

\section{CONCLUSION}

Cartilage is a very reliable and efficient material for total, subtotal and revision cases. Graft uptake rate is higher than any other graft materials in literature, and the hearing outcomes are satisfactory.

\section{REFERENCES}

1. Iacovou E, Kyrodimos E, Sismanis A. Cartilage 'shield' tympanoplasty: an effective and practical technique. Europ Arch Otorhinolaryngol 2014;271(7):1903-1908.

2. Cavaliere M, Mottola G, Rondinelli M, Iemma M. Tragal cartilage in tympanoplasty: anatomic and functional results in 306 cases. Acta Otorhinolaryngol Ital 2009;29(1): $27-32$.
3. Sheehy JL, Glasscock ME. Tympanic membrane grafting with temporalis fascia. Arch Otolaryngol 1967;86(4):391-402.

4. Levinson RM. Cartilage-perichondrial composite graft tympanoplasty in the treatment of posterior marginal and attic retraction pockets. Laryngoscope 1987;97(9):1069-1074.

5. Goodhill V. Tragal perichondrium and cartilage in tympanoplasty. Arch Otolaryngol 1967;85(5):480-491.

6. Duckert LG, Müller J, Makielski KH, Helms J. Composite autograft 'shield' reconstruction of remnant tympanic membranes. Otology Neurotol 1995;16(1):21-26.

7. Heermann J, Heermann H, Kopstein E. Fascia and cartilage palisade tympanoplasty: nine years' experience. Arch Otolaryngol 1970;91(3):228-241.

8. Aidonis I, Robertson TC, Sismanis A. Cartilage shield tympanoplasty: a reliable technique. Otology Neurotol 2005;26(5):838-841.

9. Dornhoffer J. Cartilage tympanoplasty: indications, techniques, and outcomes in a 1,000-patient series. Laryngoscope 2003;113(11):1844-1856.

10. Mürbe D, Zahnert T, Bornitz M, Hüttenbrink K. Acoustic properties of different cartilage reconstruction techniques of the tympanic membrane. Laryngoscope 2002;112(10): 1769-1776.

11. Boone RT, Gardner EK, Dornhoffer JL. Success of cartilage grafting in revision tympanoplasty without mastoidectomy. Otology Neurotol 2004;25(5):678-681.

12. Finerman WB. Causes of failure in tympanoplasty. J Natl Med Assoc 1964;56(2):136-138.

13. Dornhoffer JL. Hearing results with cartilage tympanoplasty. Laryngoscope 1997;107(8):1094-1099.

14. Gerber MJ, Mason JC, Lambert PR. Hearing results after primary cartilage tympanoplasty. Laryngoscope 2000; 110(12):1994-1999.

15. Kulkarni S, Kulkarni V, Burse K, Sancheti V, Roy G. Cartilage support for fascia graft in type I tympanoplasty. Ind J Otolaryngol Head Neck Surg 2014;66(3):291-296.

16. Kyrodimos E, Stamatiou G, Margaritis E, Kikidis D, Sismanis A. Cartilage tympanoplasty: a reliable technique for smokers. Europ Arch Otorhinolaryngol 2014;271(2):255-260. 